\title{
E-learning challenges for teaching content in environmental engineering within the framework of covid 19 an experience from the state and private university in Colombia
}

\section{Retos del e-learning para la enseñanza de contenidos en ingeniería ambiental en el marco del covid 19 una experiencia desde la universidad estatal y privada en Colombia}

DOI: $10.46932 /$ sfjdv2n3-051

Received in: May 1st, 2021

Accepted in: Jun 30th, 2021

\author{
Cuellar Rodríguez Luz Ángela \\ Universidad Santo Tomas Seccional Tunja, \\ E-mail: luz.cuellar@usantoto.edu.co \\ Rincón Pardo María Alexandra \\ Universidad Santo Tomas Seccional Tunja, \\ E-mail: mariaalexandra.rincon@uptc.edu.co \\ Benítez Ramírez Dora Marcela \\ Universidad Pedagógica y Tecnológica de Colombia, Boyacá, Colombia. \\ E-mail: dora.benitez@uptc.edu.co
}

\section{RESUMEN}

La pandemia mundial de la COVID-19 ha llevado a la suspensión de la actividad docente en muchos países. En el ámbito universitario la transformación urgente de las clases presenciales a un formato online se ha llevado a cabo de una forma que se puede calificar como aceptable en términos generales, si bien las medidas tomadas se han ajustado a la urgencia y no a una planificación pensada a priori para impartir una asignatura con una metodología completamente online. Afrontar una evaluación online masiva es algo a lo que las universidades de corte presencial no se habían enfrentado nunca desde una perspectiva institucional. El profesorado y el estudiantado, por tanto, tienen que colaborar para dar una respuesta que integre decisiones metodológicas y tecnológicas, a la vez que garantice la equidad, la seguridad jurídica y la transparencia para todos los actores, internos y externos. Este artículo tiene como objetivo analizar el tratamiento que se le da a la formación y desarrollo del aprendizaje utilizado mediante la plataforma de elearning, campus virtual o Learning Management System (LMS) en varios espacios virtuales de aprendizaje en el programa de Ingeniería ambiental de dos Universidades de diferentes características (privada y Gubernamental en Colombia) orientado a facilitar esta experiencia en las condiciones actuales (COVID 19) en que se emplean modalidades que combinan lo tutorial y lo presencial en la enseñanza/aprendizaje de contenido en los diferentes programas de igual manera al gran número de docentes que comparten este problema en este momento excepcional en todo el planeta.

Palabras clave: COVID 19, Enseñanza, Colombia, Ingeniero Ambiental.

\section{ABSTRACT}

The global COVID-19 pandemic has led to the suspension ofteaching in many countries. At the university level, the urgent transformation of classroom classes into an online format hasbeen carried out in a way that can be described as generally acceptable, although the measures taken have been adapted with 
urgency and not with a well-considered, a priori plan to teach a subject with a completely online methodology. Carrying to massive online evaluation is something that universities had never faced from an institutional perspective. Therefore, the faculty and the student must work together to provide a response that integrates methodological and technological decisions, while at the same time ensuring equity, legal certainty, and transparency for all actors, both internal and external. This article aims to analyze the treatment given to the formation and development of learning done through the e-learning platform, or Learning Management System in several virtual learning spaces in the Environmental Engineering program of two Colombian universities with different characteristics. These platforms use methods that combine tutorial and in-person teaching/learning of content in order to facilitate this experience in current conditions (COVID 19 for the large number of teachers who share this problem at this exceptional moment around the world).

Keywords: COVID 19, Teaching, Colombia, Environmental Engineer.

\section{INTRODUCTION}

The teaching and learning of the tutorial modality are attuned to that of the classroom modality, the latter of which is characterized by the physical presence of the students and the teacher in the classroom. This interactive context is essential for the teaching and oral learning of a foreign language and the development of communicative competence.

The COVID-19 pandemic has directly impacted the educational systems in every country in affecting students, households, ministries, secretariats, educational centers, educators, and administrators. The closing of schools as part of measures taken to contain the spread of the virus has more than 165 million students not attending schools, from preschools to higher education, in 25 countries in the region (UNESCO, 2020). 2

The economic and social costs of the pandemic are still unknown, but an economic crisis unprecedented in modern history is looming. It is estimated that widespread declines in GDP worldwide will affect developing countries the most. The IDB's Macroeconomic Report "Policies to Combat the Pandemic" estimates a drop in regional GDP to 5.5\%. (Nuguer, V., \& Powell, A, 2020). 4

While the economic and social costs of the pandemic are still unknown, an economic crisis never seen in modern history approaches. [SOURCE] estimates that falling GDP around the world will be felt most acutely in developing countries.The IDB's Report, "Policies to Combat the Pandemic," estimates that GDP in [Latin America and the Caribbean?] has declined 5.5\% since the start of the pandemic. (Or "The IDB's Report, "Policies to Combat the Pandemic," estimates that GDP in [Latin America and the Caribbean?] will decline by $5.5 \%$ between 20xx and 20xx).

This situation may be further aggravated in educational systems that do not have effective mechanisms for distance education in line with household characteristics 7 , which may further widen the gaps between students with greater or lesser access to them. LAC countries have launched Remote 
Education Emergency Initiatives 8 to provide short-term solutions and maintain some continuity in learning processes.

The solutions adopted have depended on the capacities and modalities of each country, as well as the content available to build an emergency model of distance education. For example, most ministries had digitized printed educational resources (e.g. textbooks, libraries, etc.), educational portals and online resources for students and teachers. Few countries had content platforms and learning management systems. It is key to understand, however, that these resources were designed for an education that would otherwise be delivered in person or semi-in person and not entirely remotely.

Most governments around the world have temporarily shut down educational institutions in an attempt to contain the spread of the COVID-19 pandemic. These nationwide closures affect about 70 percent of the world's student population.

UNESCO is supporting countries in their efforts to mitigate the immediate impact of school closures, particularly for the most vulnerable and disadvantaged communities, and to facilitate the continuity of education for all through remote learning.

Current pedagogy seeks to provide a foundation for how to reach students of the present generation most appropriately so that they master conceptual, procedural and attitudinal knowledge for their daily life and career. This includes a foreign language, in most cases English, for international communication, as an expression of culture, and a way to update or educate professionals in training in Colombia, technically or humanistically.

A classic example of this new pedagogy is the use of active learning techniques in classrooms, adding a virtual presence in a complementary social web. But the effectiveness of how to do this is neither new nor delimited; therefore, it becomes a priority in this moment for educational systems to respond to students' concerns about what they learn and how they acquire knowledge (Aguerrondo, 2009). Students' reflection has revealed some deep concerns, the most pressing of which is the need to find a fair balance between education and vocational or professional training"

In the face of current challenges, some studies examine the blended model between in-person and e-learning, which offers a new frame of reference for an educational implementation that differs from the traditional one; however, the necessary standards of excellence have not yet been achieved and the best ways to incorporate in-person learning in English with the activities of the blended model have not been explained.

In general, mastering and using e-learning is of vital importance. In environmental engineering, it allows future engineers to build their understanding of important areas, such as the dispersion of pollutants. Dr. Amparo López Jiménes of the Polytechnic University of Valencia is the pioneer in its 
implementation through water quality modeling, models of air pollutant dispersion (Gaussian Model), and the importance of chimneys and the calculation of their air intake.

On reviewing the visits that for the case of "Gaussian Pollutant Dispersion-UPV Model" on Youtube, found in the following link, https://www.youtube.com/watch?v/MNvDw0mO3LE one observes that since the video was first uploaded to this channel on November 28, 2011 to date (July 5, 2020) there have been 39,737 views which demonstrate the interest generated. However, Lopéz emphasies that experience is necessary to allow the content presented to reflect and describe the actual process; moreover, follow-up, motivating students, and planning are key to making the designed resource expressive and effective, which demonstrates a pedagogical integration of content with the situations that the environmental engineering graduate addresses. Teaching experience of the use of learning objects in environmental engineering: the transport of pollutants in natural environments. Fr. Amparo López Jiménez 2015. It is Article 1557-2866

When reviewing on July 6th, 2020 in the database SCOPUS with search keywords "environmental engineering") and "environmental engineering" you will find that yields 4 documents (one from 2000, one from 2002 and two from 2012), searching for "environmental engineering" in English yields 46,254 documents.

The professional finds more opportunities to access cutting-edge research knowledge in this area of engineering in English. Online LMS learning is currently offered, but that does not rule out blended methodology as a bet on the successful development of skills in this language. Hossein Moradimokhles \& Gwo-Jen Hwang (2020): The effect of online vs. blended learning in developing English language skills by nursing student: an experimental study, Interactive Learning Environments, DOI: 10.1080/10494820.2020.1739079.

\section{ORGANIZATION OF THE ARTICLE}

This article seeks to interpret and understand the new educational situation generated by the pressure to maintain a virtualized education during the COVID-19 era, as well as to review a set of recommendations and scenarios, helping university faculty to organize and understand virtual work in the different subjects within the immediate context of the COVID-19 crisis To this end, the remainder of the article is organized in the following sections: Data analysis that will allow the identification of a general context, reviewing the fundamentals of evaluation and e-proctoring systems in education. 


\section{METHODOLOGY}

This article was developed in a systematic review using databases and institutional repositories using searches with keywords such as "e-learning," "COVID-19 and education," and "virtual education"

\section{ANALYSIS OF THE DATA}

To say that face-to-face education is better than digital is completely erroneous. The possibilities of digital education have been brought to the table by such important institutions as the Massachusetts Institute of Technology (MIT), the University of Chicago, and the Universidad San Ignacio de Loyola. Let us reflect. Who is better prepared to face a challenge like COVID-19: the one who has studied for several years in a digital environment, and who is very familiar with this environment, or someone who is facing it for the first time? There has been talked of the democratization of knowledge, which exists and is real, but let us speak of the "commoditization" of knowledge. (Nuguer, V., \& Powell, A. 2020). 5

Knowledge 2,000 years ago was reserved for a few in educational institutions, but today it is accessible to everyone. With this, knowledge has expanded, and has done so with a marginal cost that tends to zero. Therefore, more than democratization, it is a "commoditization" of knowledge. Therefore, the most important thing in this Fourth Industrial Revolution is that we understand what is happening. We live in a present where the old does not stop dying and the news does not stop appearing. We are immersed in this transitive property where we do not know, yet, if we are analog or if we are digital. The generations that follow will live in a different reality.

A World Bank study says that, in four or five years, $65 \%$ of today's young people will have jobs that do not yet exist. Therefore, universities must prepare students for the new jobs that will arise, to use technology that has not yet been invented and to solve problems about which we do not yet know. Moreover, we must focus on the development of soft skills and digital skills, skills that the labor market will require. And what are some of those skills? Problem-solving, critical thinking, creativity, personnel management, emotional intelligence. Let us focus on creativity, which is fundamental in today's world, where young people will compete with new market forces, such as artificial intelligence and automation. For this reason, it is important to prepare them for these new challenges.

The purpose or intention of the assessment distinguishes, primarily, between the assessment of learning, which is designed to aid in the learning process y providing feedback to students (Mcalpine, 2002), and the summative assessment, which ends a learning period with a final judgment on the overall student performance (Earl, 2013. When the student is more deeply involved in the process of formative evaluation, through self-monitoring and evaluation, or by his or her peers, it is called assessment as learning (Earl, 2013). Additionally, the diagnostic evaluation tries to predict the future performance of the 
student body. As shown in Figure 1, there is a strong relationship between the time dimension and the functional dimension of the assessment.

Figure 1. Schedule of diagnostic, formative assessment. Source: based on Stalljohann (2012, p. 11).

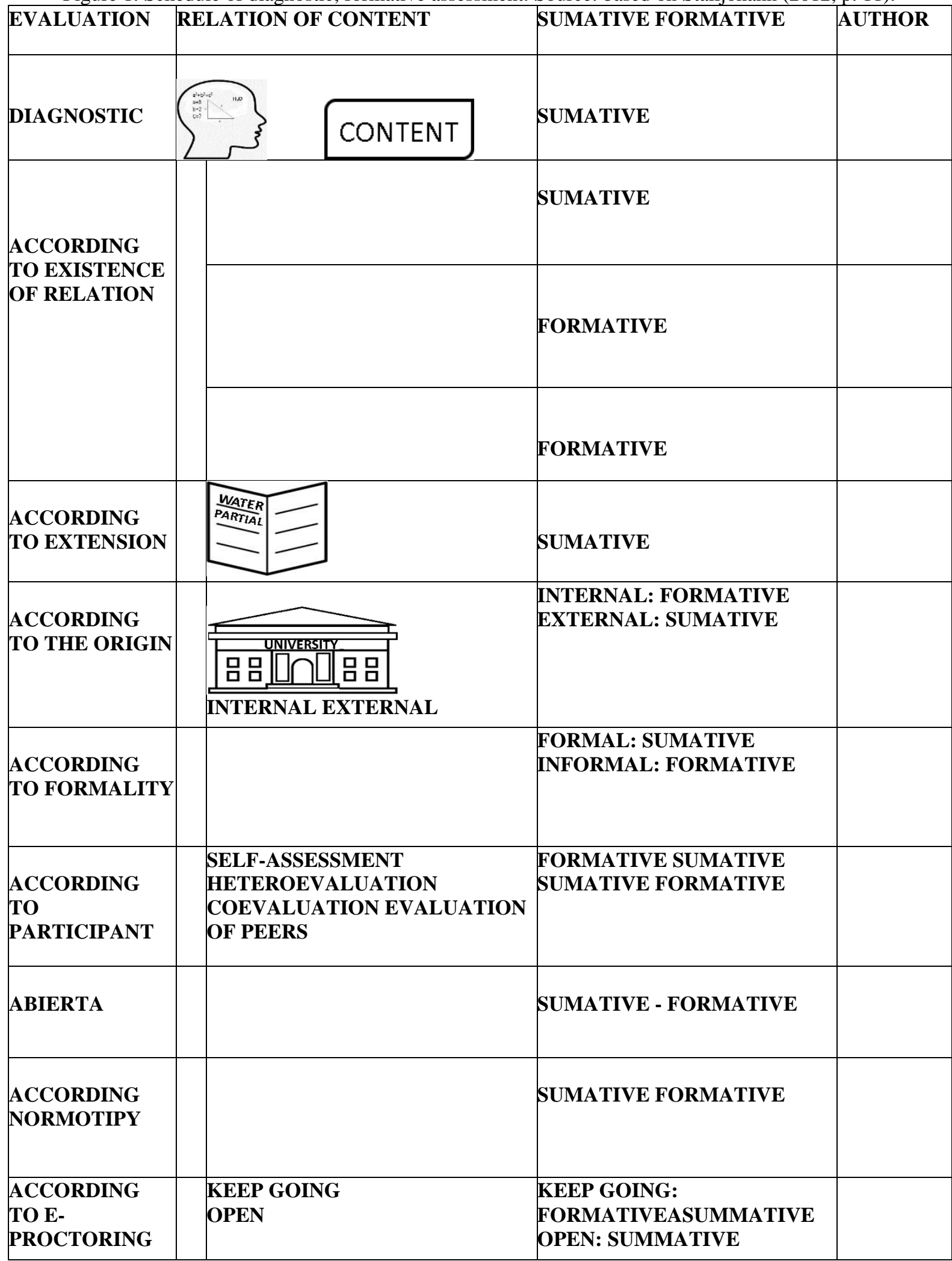


Depending on the length of the assessment, it may be a partial evaluation, which focuses on some components of a subject, or an overall evaluation, when it tries to cover all components of a student, course, program, center, etc. When the focus is on transparency, there is a range between formal and informal (Mcalpine, 2002). Formal assessment is easily recognized by the student body, as in the case of examinations or evaluable tasks. Informal evaluation accompanies other activities and is not as apparent, for example, participation in a discussion forum on the virtual campus. The subject of the assessment may be a product when it is based on the idea of the transfer of knowledge from the teaching profession to the student body, but when more emphasis is placed on competencies, the process is a more suitable subject for evaluation. However, assessing how a task has been carried out is always more complex than evaluating the outcome of a task.

According to the origin of the evaluators, we traditionally speak of internal evaluation and external evaluation. Internal evaluation is promoted and carried out from within, by the members of the teaching team themselves, while in an external evaluation, the evaluated and the evaluator belong to different bodies. This dimension may include open evaluation, which refers to the practice of obtaining and presenting credentials by demonstrating what has been learned. In this way, the process and procedures leading to the evaluation of these credentials are known, rather than maintaining and imposing a monopoly on the recognition of learning.

An example is to publish instructions, questions and headings for the evaluation of these, in such a way that any external agency wishing to evaluate students in a course (whom themselves want to be evaluated) could do so. In this situation, for a given course there is no single form of evaluation, but there can be as many forms of evaluation as there are students; the assessment of individual performance is independent, that is, it is separated from the course content and its instruction (Downes, 2012).From the perspective of the actors involved in the evaluation, a distinction is made between:

- Self-assessment: students evaluate their performance.

- Heteroevaluation: evaluators and the evaluated are not the same people

- Co-evaluation: certain people or groups mutually evaluate each other, that is, evaluators and the evaluated exchange their role alternately (Castillo Arredondo and Cabrerizo Diago, 2009). Coevaluation can also be applied to situations where students are allowed

- to assess themselves while allowing the teaching team to maintain the necessary control over final evaluations (Hall, 1995).

- Peer evaluation: the process through which students grade their peers (Falchikov, 1995).

Coevaluation can be used for summative purposes, while self-evaluation and peer evaluation tend to be used in a formative manner (Dochy, Segers and Sluijsmans, 1999). Finally, based on the normotype, 
there is a differentiation between normative evaluation and criteria evaluation., In a normative evaluation, the benchmark is the general level of a given normative group. It establishes the comparison between the performance of each student and the average performance of his group. Criterial evaluation refers to a prior criterion (evaluation criterion), or a precise and concrete determination of the expected yields (Castillo Arredondo and Cabrerizo Diago, 2009; Popham, 1980).

\section{E-PROCTORING SYSTEMS IN EDUCATION}

The development of online educational programs has evolved significantly based on pedagogical models and advances in learning technologies, but assessment or certification of learning remains one of its weakest points. In situations with few students and models focused on teacher-student interaction (Seoane-Pardo and García-Peñalvo, 2006; Seoane-Pardo and García-Peñalvo, 2008), continuous evaluation-based models are perfectly manageable and admissible. On the other hand, when the number of students grows, as is the case of the MOOC (Massive Open Online Courses) (García-Peñalvo, FidalgoBlanco and Sein-Echaluce, 2017, 2018), models based on continuous evaluation alone are no longer as feasible. then tends to extremes that lead to the development of personality assessment in specific physical locations (Shuey, 2002) or to the use of disruptive solutions based on open assessment (Downes, 2012), which are often not widely accepted in formal university training. Accordingly, there is an increase in demand for technological solutions that allow for online supervision of an evaluation (Fluck, 2019; Pathak, 2016), due as much to the limitation of having to resort to an in-person evaluation for an online education, as to studies that support the idea that unsupervised examinations have a higher potential risk of inappropriate ethical behavior or inflation (Carstairs and Myors, 2009; Prince, Fulton and Garsombke, 2009). However, few studies make an in-depth comparison of dishonest conduct in on-site testing and online testing as they are conducted (Chirumamilla, Sindre and Nguyen-Duc, 2020; Sindre and Vegendla, 2015). Remote monitoring systems are called e-proctoring systems. The use of these remote monitoring systems is conceived as an attempt to equalize the incidence of academic dishonesty between online and personality assessment tests (Harmon and Lambrinos, 2008), to lend a higher degree of confidence for both teachers and external agencies that must accredit the quality of the diplomas that are not taught person, but either $100 \%$ online or blended. There is an awareness that, as with the supervision of on-site examinations, there is no perfect virtual monitoring method. To this effect, Dawson (2016) points out that both online and in-person tests have the same threats of dishonest behavior on the part of students associated with the performance of exams themselves, adding to online testing some new threats associated with the use of technologies. However, the technological threats that may facilitate dishonest conduct in conducting testing are also appearing on in-person tests. 
Students who enrolled in-person studies do not have a reason to have the necessary technological infrastructure to conduct online assessments. Although technological penetration is broad, this is a reality to be taken into account. In this scenario, these students should be offered viable solutions (such as a temporary loan of laptops, or access to them, provided this does not violate the rules of lockdown and social distancing; as well as providing internet data cards and wifi routers). (UNESCO, 2020).

Students with special educational needs will need customized plans. A mechanism/inbox should be set up for special requests addressed to the committees/commissions of each degree. (OEI. 2020). 3

An important factor that differentiates between private and public institutions is the recruitment of students and their performance in the Saber Pro tests, The tests on the quality of undergraduate in Colombia, now called SABER PRO, have been suggested as standardized external evaluation instruments that are part of a set of processes undertaken by the National Government in an attempt to assess the quality of public education and do inspection and surveillance. Castro and Ruíz (2019) show in the first scenario the following: ..., students with higher synthetic Saber 11 indices continue their higher education at a university, compared to a technical institution... good high school students continue to be good superior education students." Concerning student recruitment, studies indicate/the data indicate/analysis indicates that private secondary and higher institutions attract more students than public entities, however, when analyzing quality (average, low and high Saber Pro scores) the public institutions in superior education . (Castro, M., \& Ruiz, J. 2019). Secondary and higher education in Colombia as observed Saber tests. Praxis \& Saber, 10(24), 341-24. https://doi.org/10.19053/22160159.v10.n25.2019.9465. Efforts are being made in the region to ensure the structuring of qualified professionals, with a commitment to developing and implementing sustainable development goals in the country.

These efforts by universities now include exceptional regulations covering the different methods of online assessment, entailing not a change in the rules governing the organization of teaching, but rather an adaptation to the online assessment. These assessments differ from the methods traditionally implemented in teaching guides, guides that will need to be modified to record, in a general way, the methodological changes and changes to the evaluation system. The normative change must be carried out without prejudice to the rights and guarantees enjoyed by students.

For virtual/distance evaluation tests, these regulations should consider general or specific contingency procedures in the case of problems that may arise (virtual classroom crash, video conferencing system, individual connectivity problems, etc.) and performance guidelines in such cases (Cordon et al., 2020). 4.

Consideration should be given to measures to preserve academic integrity and to the use of available legal mechanisms (expulsion from the test, failing grade or, where appropriate, initiation of 
disciplinary proceedings) in the event of fraudulent testing or work. The right to review grades and to challenge them in generally-established terms should also be guaranteed.

It is essential to collect evidence from assessments carried out through systems that ensure compliance with legislation on data protection and digital rights of individuals. The durability and accessibility of evidence must be guaranteed during the review period and legal custody in order to be able to deal with possible complaints from students, audits by quality agencies or regulatory compliance (Cordón et al., 2020).

\section{ONLINE EVALUATION OF THE THEORETICAL AND PRACTICAL ASPECTS OF THE SUBJECTS}

In general, when using oral examinations or written response examinations, whether synchronous or asynchronous, best practice is to avoid questions that require memorized answers or that can be looked up on the internet. They should be replaced by reflection questions, which assess students' understanding, discretion, or judgment or which require the application of some type of cognitive process, for example, causing them to do some work before submitting/providing an answer. The levels of self-identification of students for the different tests are summarized as:

- Basic level: Access to virtual platforms via ID and custom passwords is personal and non-transferable information that de facto identifies students. Improper and fraudulent use of these identification keys can have legal consequences.

- Average level: equivalent to an in-person evaluation. In a videoconference, they are asked to show the camera an identification card (code or other equivalent documents with the student's name, surname, identification number and photograph) before taking a test.

- High level: biometric identity checks are carried out. It requires prior registration of students, installation on their equipment of complementary tools, and authorization to use the webcams and/or contents of the work desk.

Online assessment scenarios for the different parts of a subject can be classified into two initial categories: synchronous and asynchronous tests. In online teaching models, it is advisable to give feedback to students on the positive aspects of the tasks they deliver and the areas with room for improvement, and to inform them of the elements on which they are being evaluated. In a continuous evaluation scenario, there is permanent student-teacher feedback. But in these exceptional situations, it is recommended to give the basic feedback that virtual platforms allow. Whenever the teaching team deems it necessary, they can convene video tutorials for the individual or group analysis of the evaluation tests. 


\section{ONLINE EVALUATION TOOLS}

So far there has been talked of online assessment strategies; this section gathers some of the most common tools that can be used to develop evaluation systems in university institutional technological ecosystems (García-Peñalvo, 2018a). Although most of these tools can be found on the different eLearning or LMS (Learning Management Systems) platforms,Moodle will be used as a reference because of its widespread implementation in university systems worldwide (https://stats.moodle.org/).

\section{STRATEGIES TO PROMOTE MOTIVATION IN ONLINE TEACHING}

The motivational role that teachers play in online teaching is crucial. The way in which teachers help to develop students' autonomy and competence occurs in two ways: directly through learning activities, and indirectly through the nature and organization of these same activities (instructional design).

A well-known model on motivation to learn (ARCS, Keller s, 2010) proposes four categories of analysis. These are the categories of attention, relevance, confidence, and satisfaction, which serve as guides for the development of teaching strategies. They consist of capturing the student's attention, establishing the relevance of the learning, increasing the student's confidence, and helping to generate feelings of satisfaction through intrinsic and extrinsic rewards. Although not created for distance education, several research papers have shown that in these new online environments, these categories also have a positive effect on student motivation.

Another important methodological framework, which helps to create motivational strategies for learning, is proposed by Ginsberg and Wlodkowski (2000). This framework consists of four principles: establishing inclusion, developing attitude, enhancing meaning and engendering competence. The use of these principles can lead to high motivation and quality for all students:

Creating inclusive environments refers to the creation of learning environments in which students and teachers feel mutual respect, through rules, procedures and structures that allow the creation of an aid community. The role of the teacher is essential to this goal, creating an environment of open communication, treating students equally, and helping all students to express their ideas and thoughts.

Developing attitudes include the development of a favorable disposition towards learning that leads to greater motivation.In other words, this principle encourages students' relevance and choices based on their individual experiences, values, strengths, and needs. This can be done by clarifying the relevance and value of the curriculum and by creating connections between learning objectives and students' aspirations and personal fulfillment.

Enhancing meaning is related to reinforcing learning in ways that interest the student, including active participation in challenging tasks and issues that encourage different points of view. These activities 
build based on previous knowledge, elicit high-quality responses, incorporate learning experiences commensurate with students' skill levels, and generate feelings of competence, satisfaction and fulfillment that promote positive motivation.

Engendering competence refers to helping the student to develop a sense of effectiveness before a required task and the feeling that they can achieve a skill/competence with mastery, and in this way, attach importance to their self-control in terms of effort and strategies used. Accordingly, students need sufficient information, guides (e.g. Study Guide), and timely feedback to create their judgments of their needs to complete the assigned task. A key to developing skills in distance learners is to provide them with self-evaluation opportunities with an appropriate level of feedback.

\section{And concerning unrealized and difficult to virtualize practices?}

As soon as the health situation and the conditions of social distancing permit, within the academic period defined for the current course, priority should be given to those practices that, not having been completed or replaced, are difficult to carry virtually due to time and cost issues, with special attention to those in their final academic year of a bachelor's or master's degree. In the worst-case scenario, except for the final year of the degree, teachers can find that the skills that could not be acquired due to the situation can be practiced and assessed; specific instructional designs, at no economic cost to students and with the endorsement of departments, degree committees and teaching bodies.

While activity in traditional laboratories is widely recognized, it is possible to implement practices wherein students approach academic work online using virtual tools such as simulations and virtual laboratories that support training in environmental engineering. Some services make it possible to create labs in the cloud and machines that can connect from anywhere, freeing physical spaces in universities. This is favorable for the institutions, especially public ones, without ignoring that private institutions have the opportunity to strengthen themselves in this regard more quickly.

There is evidence of the benefit of considering blended training. Students must overcome resistance due to their existing ties to and experience with the teacher's presence and advice. That said, a study on students' perception of this modality mentions that it is now easier to accept new technologies and faster to learn their implementation, but they indicate that not all areas are possible to implement completely virtually. Aguilar-Salinas, Wendolyn E., Fuentes-FuentesLara, Maximiliano de las, JustoLópez, Araceli, \& Rivera-Castellón, Ruth E. (2019). Students' Perception of the Blended Model of Teaching Basic Engineering Sciences. A University Case Study. University Education, 12(3), 15-26. https://dx.doi.org/10.4067/S0718-50062019000300015 
COVID-19, in public and private, means "Stay at home; but don't keep what you usually do at home." It is a call to action, it is an opportunity to innovate, to adopt simulation methodologies and virtual laboratories that are necessary and now mandatory to consider in curricula.

\section{DISCUSSION}

Online distance education continues to grow in universities today, and at this time when almost every country in the world is affected by the COVID-19 pandemic, it is one of the alternatives for students to access educational programs from their homes. Accordingly, teachers must pay attention to motivation, understanding its complexity and multifaceted nature, to design and develop successful, quality learning experiences. They should also use teaching strategies that include aspects of motivation such as meaning and expectation, which help to understand complex theories, concepts and evidence.

The motivation for online learning involves stimulating, sustaining and giving direction to the student learning, in the context of teaching designed for this purpose that determines its expression as a permanent activity for self-improvement.

Achieving motivation in the online teaching and learning process requires the development of activities that enable a proactive attitude that is conscious of inquiry and the content search. In this way, learning will implicitly bring the integration of the students' intention to acquire knowledge and develop their intellect, to the extent to which they are taught to think, to express their ideas, to reflect, to argue and to value what they learn and can thus operate with knowledge towards new and higher levels of demand that stimulate their development.

\section{CONCLUSIONS}

The COVID-19 pandemic has created an unprecedented situation in all areas of education. The state of lockdown has affected all levels of education. This article focuses on the specific case of university studies and more specifically on in-person universities that have had to make an emergency adaptation of in-person classes to a remote format that, in the best cases, have been able to integrate some of the basic principles of quality online education.

What was initially proposed as a replacement for teaching activities has inevitably led to nonclassroom assessment scenarios that have traditionally been seen as the most complex aspect of managing university degrees online, beyond continuous assessment activities, most universities, whether remote or online, base their assessment processes on formats that require the physical presence of those who choose to take these tests. 
If online teaching was already a challenge, and in many cases a shock, for the university community, remote evaluation is the biggest obstacle to completing the academic year. In addition to people's natural resistance to change, universities also face the technical limitations of systems designed to give specific IT support to mostly in-person activities and reluctance and lack of strong support from certain key players in the political and academic management of this process.

With the aim of assisting the faculty director and the student body indirectly, this article has included a set of recommendations aimed at designing online evaluation mechanisms and strategies, leading to a fair evaluation process for all. They are exactly that, recommendations, never impositions or absolute truths, because academic freedom and decision-making belong to the faculty. Professors must take their students into account in all phases of the instructional design of teaching activities and evaluations, as well as inform them in detail of the decisions made and the changes that the subject will undergo due as a consequence of the sudden causes of this crisis. In the context of these sudden changes, many teaching adaptations have had to be made in urgent conditions, so as not to paralyze academic activity.

Additionally, there is a lack of institutional experience in the area of evaluation, since these processes have not been practiced or tested remotely. Therefore, no one should expect a perfect solution with no problems and with guarantees to cover all situations that may arise. Firstly, even if a set of evaluation tools and instruments is used as a reference, they should be applied according to the learning objectives and the activities carried out. In other words, the creativity and capacity for analysis and adaptation of teachers is essential.

Furthermore, if no one is to be excluded or harmed by the conditions resulting from distance education, the possibilities and students' limitations and impacts must be known in order to establish contingency plans adapted to each case. The teacher should be aware of them and they should be integrated into the institutional strategy defined for this purpose. Finally, there is palpable fear and mistrust on the part of many of the teaching staff towards their students: they intend to exercise strict control over those being tested to detect all student practices contrary to academic ethics.

It should be kept in mind that, when it comes to the accreditation of degrees, it is not often the case that in-person tests are not free from fraudulent practices either. Therefore, the best way to minimize these problems is to resort to testing design that focuses on assessing learning and skills rather than more memory-based aspects, which has more to do with test design than with its in-person or remote location. Online assessment, therefore, requires redesigning the assessment system of the subject, that is, the best approach is not to try to replicate traditional tests in the online ecosystem. This implies having both methodological competencies and technological competences, and to know the functionalities and 
limitations of computer tools while being aware that technology is a mere facilitator of evaluation and will not by itself provide answers to the objectives of the evaluation process. Further, it should be more than a recommendation, almost an obligation, to make use of the technology that is available and institutionally supported in the university and with which the faculty and students feel comfortable and familiar, resembling as closely as possible what was planned in the classroom format. This article has consistently emphasized the benefits of a continuous, varied, and diversified assessment system to replace or minimize the weight of the final tests. It is the best option in planned online evaluation scenarios and, according to the authors, also in this emergency. There is a wealth of options, methods and evaluation tools: teachers must be motivated to move as far away as possible from an evaluation based exclusively on questionnaires which are not only one of the options that impose greater process load and performance on virtual campuses but is also not the best option from a methodological point of view. 


\section{BIBLIOGRAPHIC REFERENCES}

Earn, D. J., He, D., Loeb, M. B., Fonseca, K., Lee, B. E., \& Dushoff, J. (2012). Effects of school closure on incidence of pandemic influenza in Alberta, Canada. Annals of internal medicine, 156(3), 173-181.

El dato incluye a: Argentina, Bahamas, Barbados, Belice, Bolivia, Brasil, Chile, Colombia, Costa Rica, Ecuador, El Salvador, Guatemala, Guyana, Haití, Honduras, Jamaica, México, Panamá, Paraguay, Perú, República Dominicana, Surinam, Trinidad y Tobago, Uruguay y Venezuela. Información tomada del Instituto de Estadísticas de la UNESCO. https://en.unesco.org/covid19/educationresponse . Fecha de última actualización: 1 de mayo de 2020. Shalal, Andrea y Lawder, David (2020).

IMF chief says pandemic will unleash worst recession since Great Depression. https://www . reuters.com/article/us-health-coronavirus-imf/imf-chief-says-pandemic-will-unleash-worst-recessionsince-great-depression- idUSKCN21R1SM. April 9, 2020.

Nuguer, V., \& Powell, A. (2020). 2020 Latin American and Caribbean Macroeconomic Report: Policies to Fight the Pandemic. Inter- American Development Bank. https://doi.org/10.18235/0002284 Closing schools for covid-19 does lifelong harm and widens inequality, The Economist, April 30th 2020. OEI. (2020) Efectos de la crisis del coronavirus en la educación. Informes

OEI. Organización Estados Iberoamericanos; UNESCO (2020), Consecuencias negativas del cierre de las escuelas. Retrieved the 25/03/2020 from https://es.unesco.org/themes/educacion-situacionescrisis/coronavirus-cierres-escuelas/ consecuencias; Reimers, Fernando y Schleicher, Andreas (2020). A framework to guide an education response to the COVID-19 Pandemic of 2020. OECD.

Earn, D. J., He, D., Loeb, M. B., Fonseca, K., Lee, B. E., \& Dushoff, J. (2012). Effects of school closure on incidence of pandemic influenza in Alberta, Canada. Annals of internal medicine, 156(3), 173-181.

Shalal, Andrea y Lawder, David (2020). IMF chief says pandemic will unleash worst recession since Great Depression. https://www . reuters.com/article/us-health-coronavirus-imf/imf-chief-says-pandemicwill-unleash-worst-recession-since-great-depression- idUSKCN21R1SM. April 9, 2020.

Nuguer, V., \& Powell, A. (2020). 2020 Latin American and Caribbean Macroeconomic Report: Policies to Fight the Pandemic. Inter- American Development Bank. https://doi.org/10.18235/0002284 Closing schools for covid-19 does lifelong harm and widens inequality, The Economist, April 30th 2020.

OEI. (2020) Efectos de la crisis del coronavirus en la educación. Informes OEI.

Organización Estados Iberoamericanos; UNESCO (2020), Consecuencias negativas del cierre de las escuelas. Retrieved the 25/03/2020 from https://es.unesco.org/themes/educacion-situacionescrisis/coronavirus-cierres-escuelas/ consecuencias;

Reimers, F. M., \& Schleicher, A. (2020). A framework to guide an education response to the COVID-19 Pandemic of 2020. OECD. Retrieved April, 14, 2020. 